Proceedings

\title{
Breast-Feeding Protects Children from Adverse Effects of Environmental Tobacco Smoke ${ }^{+}$
}

\author{
Hanns Moshammer* and Hans-Peter Hutter \\ ZPH, Environmental Health, Medical University of Vienna, 1090 Vienna, Austria; \\ hans-peter.hutter@meduniwien.ac.at \\ * Correspondence: hanns.moshammer@meduniwien.ac.at; Tel.: +43-1-40160-34935 \\ + Presented at the 1st International Electronic Conference on Environmental Health Sciences, \\ 15 November-7 December 2018; Available online: https://iecehs-1.sciforum.net/. \\ Published: 14 November 2018
}

\begin{abstract}
In a cross-sectional study on 433 schoolchildren (aged 6-9 years) from nine schools in Austria, we observed associations between housing factors like passive smoking and lung function as well as improved lung function in children who had been breast-fed. The latter findings urged the question whether protective effects of breast-feeding act on environmental stressors or if they act independently. Therefore the effect of passive smoking on lung function was stratified by breast-feeding. Detrimental effects of passive smoking were significant but restricted to the group of 53 children without breast-feeding. Breast feeding counteracts the effect of environmental stressors on the growing respiratory organs.
\end{abstract}

Keywords: breast-feeding; passive smoking; lung function; early life exposures; protective factors

\section{Introduction}

We have previously reported on 433 schoolchildren (aged 6-9 years) from nine schools in Austria. We have found associations between indoor air quality in the schools and lung function of the children [1], between organophosphate flame retardants in the dust of classrooms and cognitive performance of the children [2], and between household factors like passive smoking reported in a questionnaire by the parents and lung function [3]. We also observed better lung function in children who had been breast-fed. The household factor that most strongly reduced lung function was "number of smokers in the household".

Based on these findings, the question arose whether protective effects of breast-feeding act on environmental stressors or if they act independently. To that end, an analysis of the effects of "number of smokers" on lung function was performed stratified by reported breast-feeding. In addition, the effect of breast-feeding was investigated for different durations of breast-feeding. In this analysis "number of smokers" served as an indicator of environmental tobacco smoke (ETS).

\section{Materials and Methods}

In a nation-wide project, nine Austrian primary full-day schools from Vienna, Lower Austria, Styria, and Carinthia were selected and included in a cross-sectional study. Indoor air quality was assessed in the schools and linked to details of construction and also to siting of the school buildings. Chemical analyses were performed in the air (gaseous pollutants), in the airborne dust (PM2.5), and in samples from settled dust.

In 2-4 classes (1st and 2 nd grade) children were invited to participate in health examinations. Parents provided informed consent. Children were instructed about the planned procedures and 
could abstain from any examination. Headmasters and teachers supported the study and distributed information material, consent forms, and questionnaires to the parents in advance.

Here we report on the effects of breast-feeding as reported by the parents (usually the mother) and on passive smoking on lung function. Information on breast-feeding was obtained both in a binary format ("ever breast-feeding: yes/no") and as an ordinal variable (Table 1). Passive smoking was asked through several questions: "How many cigarettes are usually smoked in the home per day?"/"How many smokers are in the household?"/"Does the mother smoke?"/"Did the mother smoke during pregnancy?"/“Did the mother smoke while breast-feeding?"/“Does the father smoke?"

Lung function testing was performed according to the protocol of the American Thoracic Society [4], except for the minimum exhalation time of $6 \mathrm{~s}$ (which is not feasible for children). Both volume and flow parameters were documented: Forced vital capacity FVC, forced expiratory volume in the first second (FEV1) and in the first half second (FEV0.5), peak expiratory flow (PEF), maximal mean expiratory flow (MMEF), maximal expiratory flow at 25\% of FVC (MEF25), maximal expiratory flow at 50\% of FVC (MEF50), and maximal expiratory flow at 75\% of FVC (MEF75). All lung function tests were conducted between 8:30 and 12:30 a.m.

Age (in years), height (in $\mathrm{cm}$ ), weight (in $\mathrm{kg}$ ), and sex of each participating child was noted. For each lung function parameter at first a model was developed that included the exposure of interest, all anthropometric measures also including weight squared [5]. Anthropometric measures were removed step by step from the model (starting with that with the highest $p$-value) if they did not contribute to the model fit $(p>0.2$ or $p>0.1$ and no relevant effect on the point estimate of the exposure effect). All statistical analyses were done with STATA 13.1 SE [6].

\section{Results and Discussion}

Table 1 presents the sample of 433 schoolchildren. Not all questions have been answered by all parents. Not all children provided valid FEV1 results. Therefore also FEV0.5 was investigated.

Table 1. Description of the sample.

\begin{tabular}{ccc}
\hline Parameter & Number & Mean \pm Std. Dev. \\
\hline Age (years) & 433 & $7.3 \pm 0.6$ \\
Height (cm) & 433 & $127.0 \pm 6.9$ \\
Weight (kg) & 433 & $27.5 \pm 6.1$ \\
FVC (L) & 433 & $1.6 \pm 0.3$ \\
FEV1 (L) & 337 & $1.6 \pm 0.3$ \\
FEV0.5 (L) & 433 & $1.2 \pm 0,2$ \\
PEF (L/s) & 433 & $3.0 \pm 0.7$ \\
MEF75 (L/s) & 433 & $3.0 \pm 0.7$ \\
MEF50 (L/s) & 433 & $2.3 \pm 0.6$ \\
MEF25 (L/s) & 433 & $1.3 \pm 0.4$ \\
MMEF (L/s) & 433 & \\
\hline Sex & 433 & \\
\hline Male & 215 & \\
Female & 218 & \\
\hline Number of Smokers & 420 & \\
\hline 0 & 207 & \\
1 & 147 & \\
2 & 64 & \\
3 & 2 & \\
\hline Less than 2 months & 426 & \\
2-4 months & 53 & \\
5-6 months & 79 & \\
More than 6 months & 76 & \\
\hline Duration of breast-feeding & 130 & \\
\hline Never & & \\
\hline & & \\
\hline
\end{tabular}


While 133 mothers (of 431) reported current smoking, only 94 (of 431) reported smoking during the first year of the child, only 42 (of 432) during breast-feeding and only 52 (of 433) during pregnancy. Although early life ETS exposure (pre and post birth) is a strong predictor of lung function [7] and this finding was also confirmed in this sample [3], the numbers were too small to investigate interaction effects meaningfully. For example, only 17 mothers reported smoking in the first year of the child and never breast-feeding, 11 smoking during pregnancy and never breast-feeding. The number of smokers in the household was more evenly distributed and therefore was selected as the best marker of ETS exposure for the analysis of protective effects of breast-feeding.

Detrimental effects of smokers in the household were significant but restricted to the group of 53 children without breast-feeding (Figure 1). After controlling for age, sex, height, and weight, lung-function improved with breast-feeding and that effect grew stronger with the duration of breast-feeding (Figure 2).

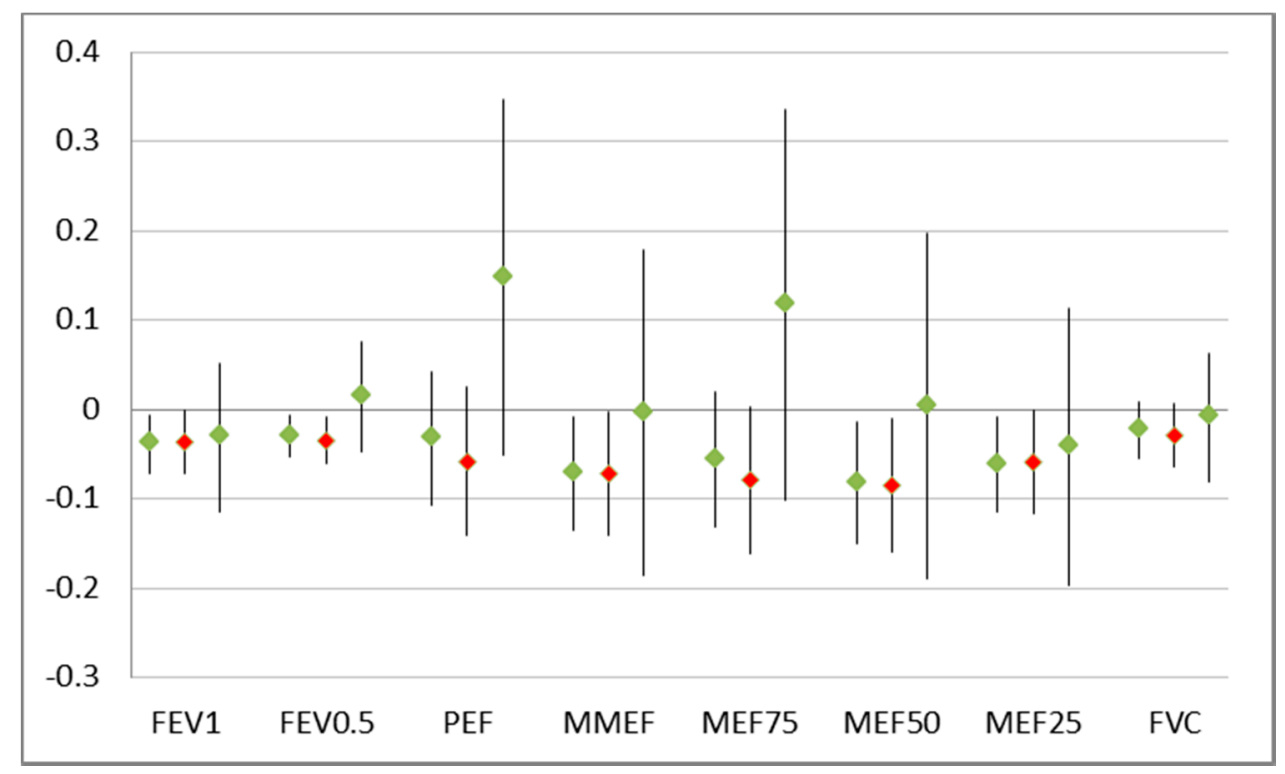

Figure 1. Results of linear regression on number of smokers on lung function parameters: change in liter (FVC, FEV1, FEF0.5) or in liter/sec. (other parameters) per smoker. Point estimates 95\% confidence interval: all 433 children (left), 53 children without breast-feeding (red marker, middle), and 380 breast-fed children (right).

Breast-feeding counteracts the effect of environmental stressors like environmental tobacco smoke on the growing respiratory organs. Although most of the children were breast-fed and thus the power to detect an effect of ETS exposure would have been sufficient in general no effect of ETS was visible in that group. The well-known impact of ETS on poor lung function that was evident in the overall group was driven solely by the fewer children without breast-feeding (Figure 1).

The reverse was not true (data not shown): Breast-feeding (and especially longer breast-feeding) improved all lung function parameters no matter if there was a smoker in the household or not. Breast-feeding likely protects not only from the adverse effects of ETS but also from other factors. Other environmental causes of poorer lung function, e.g. air pollution, were visible in that population [3] but generally too weak to meaningfully allow the investigation of interaction effects. But more generally protective effects from breast-feeding are to be expected also regarding these other and many more factors. 


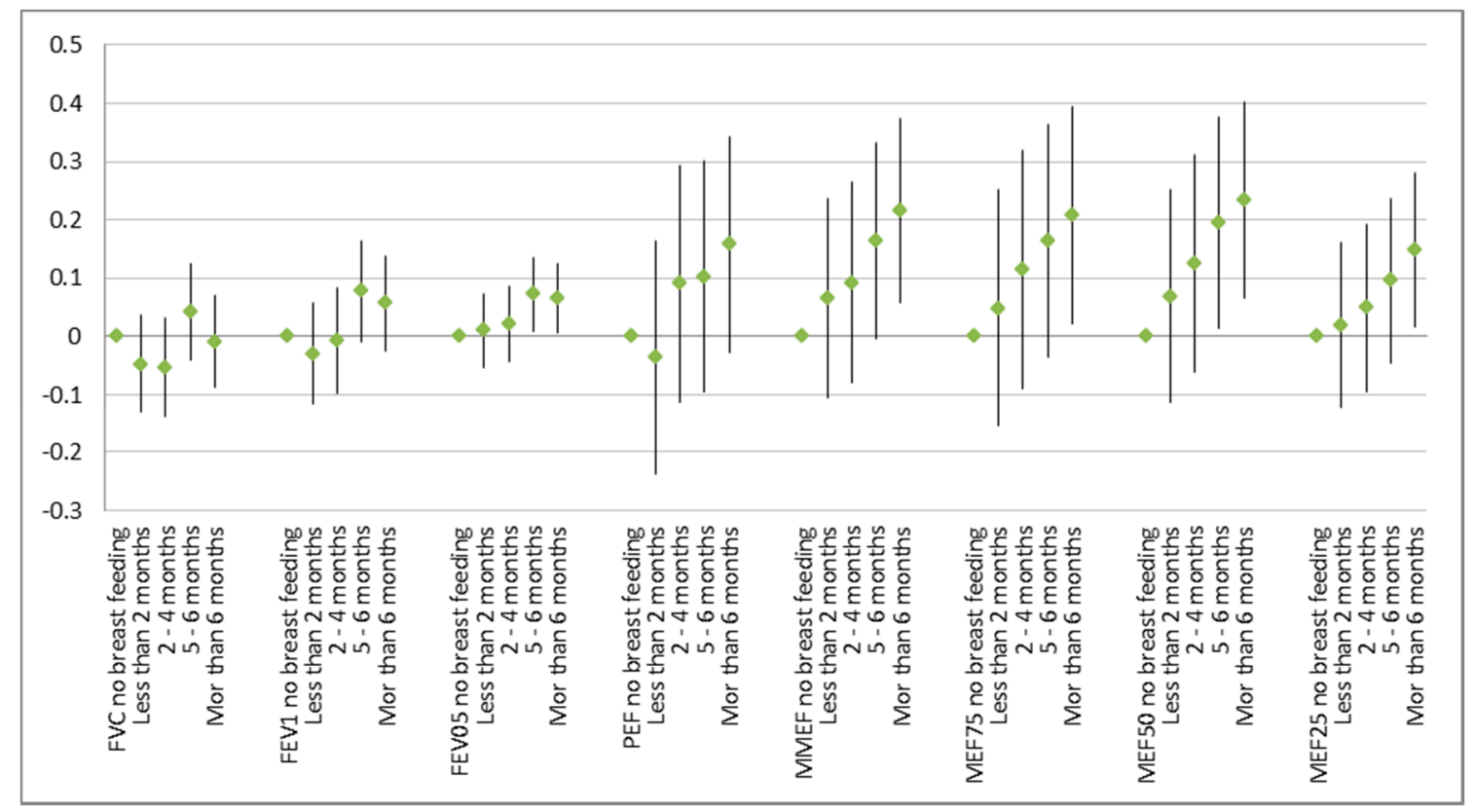

Figure 2. Effect of duration of breast-feeding on lung function in comparison to no breast-feeding: Point estimates and 95\% confidence intervals in liter (FVC, FEV1, and FEV0.5) or in 1/s.

Author Contributions: H.M. conceived the paper, performed the statistical analyses, and wrote the first draft. H.-P.H. was the principal investigator of the field study and provided the data. Both authors discussed and finalized the paper.

Funding: This research received no external funding.

Conflicts of Interest: The authors declare no conflict of interest.

\section{References}

1. Wallner, P.; Kundi, M.; Moshammer, H.; Piegler, K.; Hohenblum, P.; Scharf, S.; Frohlich, M.; Damberger, B.; Tappler, P.; Hutter, H.-P. Indoor air in schools and lung function of Austrian school children. J. Environ. Monit. 2012, 14, 1976-1982.

2. Hutter, H.-P.; Haluza, D.; Piegler, K.; Hohenblum, P.; Fröhlich, M.; Scharf, S.; Uhl, M.; Damberger, B.; Tappler, P.; Kundi, M.; et al. Semivolatile compounds in schools and their influence on cognitive performance of children. Int. J. Occup. Med. Environ. Health 2013, 26, 1-8.

3. Moshammer, H. Household factors influencing lung function in Austrian school children. Int. J. Environ. Health 2008, 2, 356-364.

4. American Thoracic Society. Standardization of spirometry-1987 update. Am. Rev. Respir. Dis. 1987, 136, 1286-1298.

5. Hochgatterer, K.; Moshammer, H.; Haluza, D. Dust is in the air: Effects of occupational exposure to mineral dust on lung function in a 9-year study. Lung 2013, 191, 257-263.

6. STATA SE Vers. 13.1; StataCorp: College Station, TX, USA, 2013.

7. Moshammer, H.; Hoek, G.; Luttmann-Gibson, H.; Neuberger, M.; Antova, T.; Gehring, U.; Hruba, F.; Pattenden, S.; Rudnai, P.; Slachtova, H.; et al. Parental Smoking and Lung Function in Children. An International Study. Am. J. Respir. Crit. Care Med. 2006, 173, 1255-1263.

(C) 2018 by the authors. Licensee MDPI, Basel, Switzerland. This article is an open access article distributed under the terms and conditions of the Creative Commons Attribution (CC BY) license (http://creativecommons.org/licenses/by/4.0/). 